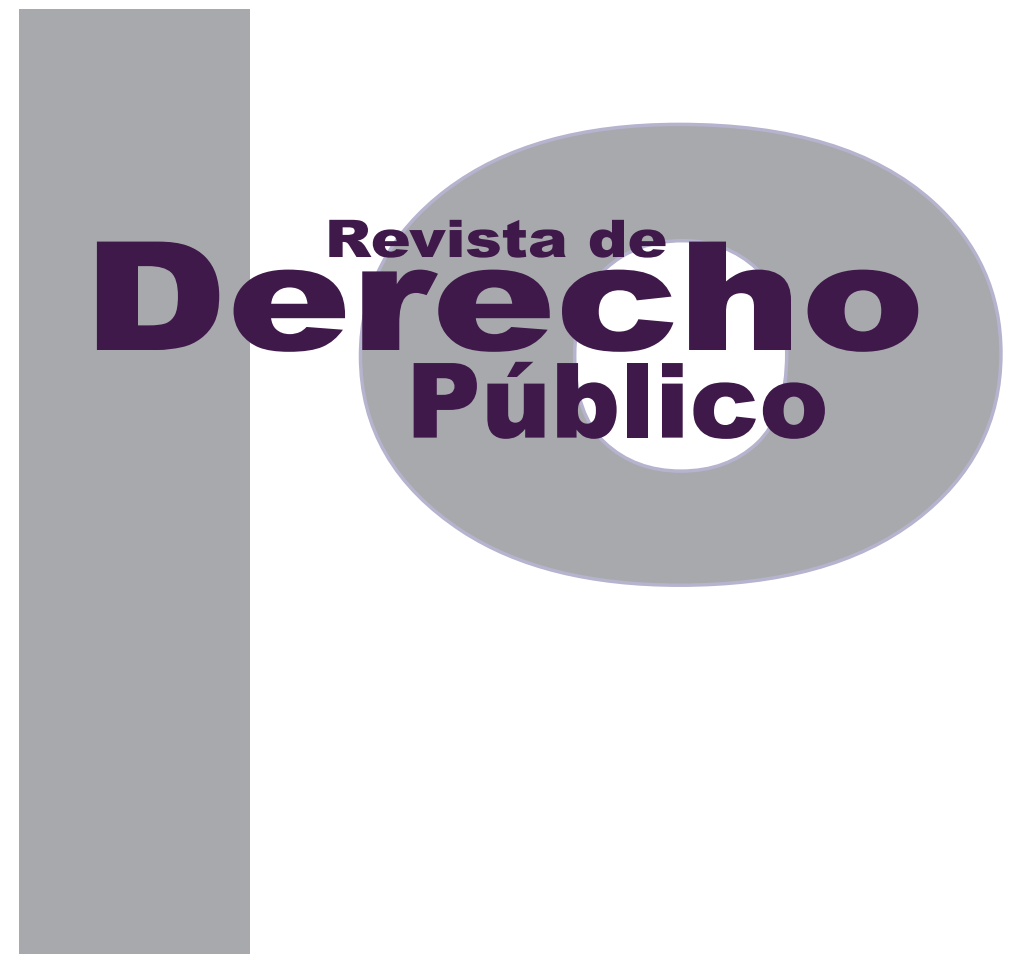

\title{
ASPECTOS JURÍDICOS RELATIVOS A LA UTILIZACIÓN DEL ESPECTRO ELECTROMAGNÉTICO Y RADIOELÉCTRICO Y SU IMPORTANCIA EN LAS TELECOMUNICACIONES POR SATÉLITE
}

CAROLINA Rincón CORTÉS

Universidad de los Andes

Facultad de Derecho

Revista de Derecho Público N. ${ }^{\circ} 30$

Enero - Junio de 2013. ISSN 1909-7778 


\title{
Aspectos jurídicos relativos a la utilización del espectro electromagnético y radioeléctrico y su importancia en las telecomunicaciones por satélite
}

\author{
Carolina Rincón Cortés*
}

\section{RESUMEN}

El escrito que a continuación se presenta tiene como objeto la descripción y el análisis de la normatividad internacional y nacional respecto al funcionamiento de las telecomunicaciones a través del espectro electromagnético y radioeléctrico. Exaltando las exigencias del mundo actual, surge la necesidad de comprender los motivos por los cuales la existencia de un cuerpo normativo resulta imprescindible para la operación de dichos espectros. Las características inherentes a los campos eléctricos antes aludidos permiten que, en la actualidad, las sociedades modernas puedan difundir todo tipo de mensajes en un lapso de tiempo ínfimo, ya sea mediante sistema inalámbrico, alámbrico, radial, televisivo, entre otros. En este sentido, las dificultades que eventualmente se puedan llegar a presentar deben ser contenidas en cuerpos normativos e instituciones que garanticen

\begin{abstract}
The presented thesis concerns the description and analysis of the international and national regulations of the electromagnetic and radio electric spectrum. Exalting the demands of today's world, the need to comprehend the reasons for the existence of a regulatory body, is essential for the operation of telecommunications through the spectrum. The inherent characteristics and properties of these energetic fields, allow modern societies to transmit all sorts of messages in a very short period of time; whether if they are conveyed through televised means or radio means etc. In this sense, the difficulties that may arise, have to be contained in laws and institutions that posses the capacity to coordinate and harmonize the telecommunication service. In this order of ideas, the topic developed in this work, is limited exclusively to satellite systems of telecommunications; clearly, under the frame
\end{abstract}

\footnotetext{
Abogada de la Universidad de los Andes (2012), octavo semestre de Ciencia Política en la misma Universidad. Curso en Derecho Internacional Económico y Derechos Humanos de American University, curso de Teoría y Práctica del Derecho de los Negocios Internacionales de la Universidad Complutense de Madrid. Abogada junior de la firma Valbuena, Gamboa, García, Cardona \& De la Rosa, área corporativa (septiembre 24 de 2012 - mayo 25 de 2013). Especialista jurídica de la multinacional fEMSA Coca Cola (junio 4 de 2013).
} 
la coordinación y la armonía en el servicio de las telecomunicaciones. En este orden de ideas, el tema a desplegar en este trabajo se limitará de manera exclusiva a las telecomunicaciones que se dan en el plano satelital, claramente, en el marco de los ordenamientos internacional y nacional.

Palabras Clave: espectro electromagnético, espectro radioeléctrico, ondas electromagnéticas, frecuencias, telecomunicaciones, sistema satelital, Unión Internacional de Telecomunicaciones. of international and national regulations concerning the spectrum.

KEY WORDS: electromagnetic spectrum, radio electric spectrum, electromagnetic waves, frequencies, telecommunications, satellite system, International Telecommunication Union. 


\section{SUMARIO}

Introducción - I. PREGUNTA DE INVESTIGACIÓN - II. ESQUEMA - III. DEFINICIÓN CONCEPTUAL DE LOS ESPECTROS - A. espectro electromagnético - B. espectro radioeléctrico - IV. SISTEMA SATELITAL DE TELECOMUNICACIONES - V. NORMAS INTERNACIONALES APLICABLES AL MANEJO DEL ESPECTRO ELECTROMAGNÉTICO Y DEL ESPECTRO RADIOELÉCTRICO - A. Constitución y Convenio Internacional de Telecomunicaciones y creación de la Unión Internacional de las Telecomunicaciones - B. Tratado de Montreux de 1965 y Conferencia de Plenipotenciarios de la Unión Internacional (Málaga-Torremolinos, 1973) - C. Reglamento de las Radiocomunicaciones de la UIT de 1992 - D. Tratado de Nairobi de 1982 - VI. NORMAS NACIONALES APLICABLES AL MANEJO DEL ESPECTRO ELECTROMAGNÉTICO Y DEL ESPECTRO RADIOELÉCTRICO - A. Definición constitucional - B. Asignación de frecuencias - C. Uso - D. Agencia Nacional del Espectro - VII. REFLEXIONES FINALES - Bibliografía. 


\section{Introducción}

Los procesos de transmisión y recepción de ideas dependen actualmente de las múltiples posibilidades que los distintos canales de telecomunicación ofrecen. Es decir, si bien en nuestras cabezas existe un sinnúmero de pensamientos, si no lográramos una representación de estos a través de la comunicación no habría evidencia alguna de ellos. Es precisamente por lo anterior que el desarrollo de la humanidad, como especie, gravita alrededor de factores tales como la forma en que nos comunicamos. En un principio bastó con la comunicación oral, posteriormente se sumó la comunicación escrita y finalmente las imágenes. No obstante, a pesar de ser estos los pilares esenciales de la transmisión de ideas, las necesidades del hombre condujeron a su extensión a través de los canales de comunicación. Dar a conocer el modo en que dicha extensión se ha logrado, la función que en esto han cumplido los nuevos avances tecnológicos, y la necesidad de normas que los regulen es el objetivo del presente trabajo. En otras palabras, lo que sigue se ocupará de todos aquellos aspectos que definen la forma en que las telecomunicaciones funcionan en la actualidad, con especial énfasis en el aspecto jurídico, ya que la existencia de un conjunto de normas que sistematizan y reglamentan el uso de estos campos eléctricos es lo que permite que efectivamente se pueda dar la actividad del mundo de las telecomunicaciones.

En consecuencia, se examinarán los aspectos técnicos que permiten que hoy en día podamos intercambiar información vía internet, celular, entre otros, con el fin de vislumbrar de la ma- nera más precisa el papel que juegan elementos tales como el espectro electromagnético y el espectro radioeléctrico en el ejercicio cotidiano de las telecomunicaciones y el intercambio de información. La comprensión de nociones como las acabadas de enunciar permitirá entender lo que, en últimas, no pasa de ser un ejercicio del lenguaje a través de canales que, a pesar de ser invisibles e imperceptibles al ojo humano, determinan el funcionamiento de la sociedad como la conocemos hoy en día.

Así pues, resulta pertinente estructurar dos aproximaciones: la primera, ya mencionada, se relaciona con todo lo relativo a los aspectos técnicos y básicos de la composición y funcionamiento de los espectros electromagnético y radioeléctrico; la segunda, en cuyo desarrollo se cimenta este trabajo, tiene que ver con los elementos jurídicos reguladores de la actividad que se realiza en torno a ambos tipos de espectro. Se examinará, tanto la órbita internacional como la nacional para brindar un concepto general acerca de la forma en que la ley regula las acciones que se pueden desarrollar en uso del espectro radioeléctrico y electromagnético, en especial aquellas relacionadas con el ejercicio de las telecomunicaciones a nivel satelital.

\section{PREGUNTA DE INVESTIGACIÓN}

Las pregunta de investigación que sirve de piedra angular y que constituye la guía de este trabajo es la siguiente: ¿cuál es la relevancia que tienen para el funcionamiento de las telecomunicaciones a nivel satelital las regulaciones existentes, tanto a nivel nacional como internacional? 


\section{ESQUEMA}

Para responder el anterior interrogante el trabajo se estructuró en dos bloques o ejes. El primero es una aproximación técnica a través de la cual se lleva a cabo una conceptualización de las definiciones del espectro electromagnético y del espectro radioeléctrico. El segundo es un acercamiento normativo en el que se examinan las normas internacionales aplicables al manejo del espectro electromagnético y el espectro radioeléctrico haciendo referencia a la noción del recurso órbita espectro (ROE), como base para comprender y asimilar lo relacionado con el trámite ante la Unión Internacional de Telecomunicaciones (UIT) y la relación existente entre las frecuencias producidas en el marco del espectro electromagnético/radioeléctrico y la órbita geoestacionaria. En cuanto a las normas de carácter nacional se mirará, en particular, la forma en que la ley concibe ambos tipos de espectros, el modo como se asignan y la manera como se maneja el tema en términos jurídicos desde la Agencia Nacional del Espectro. Finalmente, y haciendo parte del último bloque, se aborda el aspecto analítico del trabajo, a saber: la prescindencia de un cuerpo normativo referente a la sistematización y regulación sobre ambos tipos de espectro.

\section{DEFINICIÓN CONCEPTUAL DE LOS ESPECTROS}

\section{A. Espectro electromagnético}

La noción que se adoptó, para efectos de la comprensión del espectro electromagnético en el marco de este escrito, es la siguiente: el espectro electromagnético puede ser concebido como el campo energético compuesto de ondas electromagnéticas organizadas en función de sus frecuencias o longitudes de onda ${ }^{1}$. Dado que dicha noción presenta dificultades en cuanto a su entendimiento, es menester realizar una descomposición de la misma.

Según Bernardo Fontal, el universo, tal como lo conocemos, contiene materia y energía. Estos componentes están relacionados a través de la famosa ecuación de Albert Einstein: $\mathrm{E}=\mathrm{mc2}$, donde $E$ representa la energía, $m=$ la masa de la materia y $\mathrm{c}=$ la velocidad de la luz. La luz y otras radiaciones como, por ejemplo, la radiación electromagnética son expresiones de la energía que se manifiestan en forma ondulatoria y viajan por el espacio a la máxima velocidad permitida, a saber: la velocidad de la luz. Al encontrarnos en la Tierra, el Sol nos provee directa o indirectamente la mayor parte de la energía que los seres vivos requerimos para poder sobrevivir. La manera directa nos llega en forma de luz o radiación y la indirecta a través de procesos que ocurrieron con luz y radiación hace mucho tiempo "en la formación de enlaces quí-

"Espectro electromagnético". (s. f.). Recuperado el 29 de mayo de 2012 a las 7:00 p. m. de: http://www.gobiernoenlinea.gov.co/web/ guest/encyclopedia/- 
micos de materiales que se convirtieron en los actuales combustibles fósiles" ${ }^{2}$. En el caso de la radiación electromagnética, esta es de suma trascendencia para la supervivencia humana en la medida en que nos encontramos en constante contacto con ella:

cuando observamos una noche estrellada o caminamos durante el día, todo lo que vemos con nuestros ojos, el calor del sol en nuestra piel, la comunicación con nuestros amigos por el celular, cuando escuchamos la radio FM o cuando calentamos la comida en el horno de microondas, son situaciones donde la radiación electromagnética está jugando una parte importante y afectando nuestras vidas. La sociedad moderna a través de la ciencia y la tecnología ha sabido sacarle provecho a esa fuente de energía, como también a utilizarla para transmitir información, todo a la velocidad de la luz ${ }^{3}$.

La radiación electromagnética proviene de dos fuentes distintas: la primera, de origen natural como el Sol y las tormentas eléctricas; la segunda, de origen artificial como, por ejemplo, las líneas de transporte, distribución eléctrica, entre otros. Este tipo de radiación se manifiesta a través de longitudes de onda, las cuales pueden ser concebidas como la expresión más clara de propagación de la radiación electromagnética.

Esta se mide en Hertzios ${ }^{4}$ y su unidad de tiempo

2 FontAL, Bernardo, El espectro electromagnético y su aplicaciones, Caracas, Escuela Venezolana para la Enseñanza de Química, 2005, p. 8.

3 Ibídem, p. 4

$4 \quad$ Hertzios o Hertz es la unidad internacional de medida del espectro electromagnético. Se simboliza $\mathrm{Hz}$ (escrito sin punto). Un Hertz representa un ciclo por cada segundo (unidad de tiempo), entendiendo ciclo como la repetición de un evento. corresponde al segundo. Dependiendo de qué tan larga o corta sea la onda electromagnética se podrá transmitir un tipo de región distinto (esto se explicará más adelante). Es importante comentar que, a diferencia de otro tipo de ondas, como por ejemplo las mecánicas, las ondas electromagnéticas no necesitan de un medio para poder propagarse, es decir, no requieren de un vehículo conductor para desplazarse de un lugar a otro, naturaleza que les permite expandirse en escenarios tales como el espacio o incluso en el mismo vacío. Como se detallará más adelante, cuando las ondas electromagnéticas se desplazan por medio de cables, la utilización y control de los mensajes difundidos no ofrecen mayor problema; no obstante, cuando se desarrollan en el espacio (en el marco de un sistema satelital), surge una serie de complicaciones, dentro de las que se ubica la siguiente: no existen límites fijos del número de ondas electromagnéticas que puedan recibirse sin interferencia de otras que coincidan en el mismo tiempo y destino ${ }^{5}$. De ahí emana la necesidad de crear un sistema de coordinación en la figura de protocolos y normas internacionales que eviten estos inconvenientes.

La principal atribución que posee una onda electromagnética se denomina frecuencia o banda de frecuencia, intervalo que es único para cada tipo de onda (como si fuera una huella dactilar), así, las ondas de radio tienen una frecuencia distinta de la de las ondas de televisión. Por frecuencia puede comprenderse la repetición que se da de las ondas electromagnéticas. Enton-

5 "Onda electromagnética".(s. f.). Recuperado el 14 de mayo de 2012 alas 4:15 p. m. de: http://www.tuobra.unam.mx/publicadas/020428174637DERECHO.html. 
ces, entre más alta sea la frecuencia mayores repeticiones tendrá una onda electromagnética determinada y, por lo tanto, el servicio a prestar dependerá de qué tantas repeticiones se puedan llegar a dar ${ }^{6}$.

Teniendo estas nociones claras, en palabras figuradas se puede decir que el espectro electromagnético puede ser visto como una regla de grandes dimensiones, la cual no mide centímetros ni metros sino frecuencias; es un rango compuesto por luz y radiación electromagnética, que no tiene límite inferior o superior. A continuación se procede a explicar el concepto de espectro radioeléctrico.

\section{B. Espectro radioeléctrico}

De acuerdo con lo planteado por la uाT, el espectro radioeléctrico puede "ser concebido como aquellas frecuencias del espectro electromagnético usadas para los servicios de difusión, servicios móviles, de policía, bomberos, radioastronomía, meteorología y fijos. Este (...) no es un concepto estático, pues a medida que avanza la tecnología se aumentan (o disminuyen) rangos de frecuencia utilizados en comunicaciones, co-

6 La propagación de las ondas se ve claramente afectada por algunos fenómenos físicos dentro de los que se encuentran la reflexión, la refracción, la difracción, la interferencia y el efecto doppler. La primera de estas ocurre cuando una onda, al encontrarse con un nuevo medio que no puede atravesar, cambia de dirección. La refracción se presenta cuando una onda cambia de dirección al entrar en un nuevo medio en el que viaja a distinta velocidad. Por su parte, la difracción se da cuando una onda, al topar con el borde de un obstáculo, deja de ir en línea recta para rodearlo (esto sucede con las ondas que presentan una gran longitud y tienen una frecuencia muy alta). La interferencia tiene lugar cuando dos ondas se combinan al encontrase en el mismo punto del espacio. Finalmente, el efecto doppler se produce como resultado del movimiento relativo entre la fuente emisora de las ondas y el receptor de estas. rresponde al estado de avance tecnológico"7. El autor español Miguel Sánchez ${ }^{8}$ define el espectro radioeléctrico como aquella parte del espectro electromagnético que abarca desde los 9 kilohertzios hasta los 3000 megahertzios y cuya utilización para aplicaciones de radiocomunicaciones está regulada por acuerdos internacionales, celebrados en el marco de la Unión Internacional de las Telecomunicaciones.

Este tipo de espectro cuenta con una variedad de bandas de frecuencias que sirven para la prestación de servicios de radiocomunicaciones $y$ se dividen en frecuencias terrestres y frecuencias satelitales ${ }^{9}$. Para efectos de este escrito, la radiocomunicación debe ser entendida como un sistema de telecomunicaciones en el cual, de acuerdo con las características relativas a las frecuencias, se pueden explotar servicios como las transmisiones de televisión, radio, radar y telefonía móvil. De igual forma, las frecuencias del espectro radioeléctrico sirven para los servicios de radionavegación y de emergencia.

Adicionalmente, resulta menester comentar que las longitudes de onda son las que permiten la ejecución de distintas actividades. Por ejemplo, una onda con grandes longitudes puede atravesar montañas y recorrer largas distancias. Empero, si la longitud es muy corta, la onda puede

7 Corte Constitucional, sentencia C-310 de 1996.

8 SÁnCHEZ, Miguel, "La regulación del uso del espectro radioeléctrico" en Cremades, Javier (coordinador). Derecho de las Telecomunicaciones. Madrid: La Ley - Actualidad y Ministerio de Fomento, 2005, pp. 795-820.

9 Acorde con la ubicación de las bandas dentro del espectro radioeléctrico, las características naturales de esa banda definen las aplicaciones que en ellas pueden explotarse. Para efectos prácticos, las aplicaciones se dividen en terrestres y satelitales. 
ser detenida por objetos como la lluvia, creando el fenómeno llamado rain fade. Las bandas Ku y Ka, cuyas frecuencias son muy elevadas, permiten transmitir más información por segundo ya que se puede depositar una mayor cantidad de esta en la onda. Es importante recalcar que este tipo de bandas de frecuencia, incluyendo la banda $\mathrm{C}$, son empleadas para los sistemas satelitales de telecomunicación, pues como se acabó de comentar cuentan con un gran potencial de transmisión de información. A pesar de los inconvenientes que se pueden presentar, gracias a los avances tecnológicos existen satélites en órbita geoestacionaria, como por ejemplo el KASAT, que supera los obstáculos del efecto rain fade y logra de manera efectiva difundir sus servicios de internet a Europa y al Medio Oriente a través de una banda Ka.

De acuerdo con lo anterior, hasta este momento se pueden identificar tres puntos relevantes que articulan ambos tipos de espectro: 1) el espectro radioeléctrico hace parte del espectro electromagnético, 2) su utilización está dirigida al desarrollo de las radiocomunicaciones, y 3) su regulación internacional reposa en manos de la Unión Internacional de Telecomunicaciones.

\section{SISTEMA SATELITAL DE TELECOMUNICACIONES}

Las ondas electromagnéticas poseen características inherentes que les permiten difundirse a través de distintos medios. Así pues, no resulta imprescindible para su desplazamiento el empleo de vehículos como por ejemplo el aire, el agua, etc. Su difusión puede darse a través del vacío, razón por la cual en el espacio, especialmente en lo relacionado con los sistemas satelitales de telecomunicación, su funcionamiento es posible. Como se comentó con anterioridad, si bien no existen inconvenientes de índole técnica en la propagación de las ondas electromagnéticas cuya transmisión se hace a través de cables o alambres, cuando dicha trasmisión se da en el vacío, problemas como las interferencias se convierten en contrariedades constantes. En consecuencia, la expedición de normas y la creación de instituciones que regulan y controlan dichas contrariedades se convierten en una prioridad, ya que el sistema satelital de telecomunicaciones reposa de manera exclusiva en el trabajo realizado por dichas instituciones y su juiciosa aplicación de las normas internacionales. Teniendo esto claro, a continuación se hace referencia a la forma en que opera el sistema satelital de telecomunicaciones.

En octubre de 1945, Arthur Clark señaló las posibilidades de que los canales de teléfono y de radiodifusión dependieran únicamente de satélites artificiales. Resaltó en particular las propiedades de la órbita satelital conocida como la órbita de los satélites geoestacionarios. Esta clase de órbita se encuentra a $35.786 \mathrm{~km}$ sobre la línea ecuatorial de la Tierra. Si se ubica un satélite a esa altura, un observador desde la Tierra puede verlo estacionado, ya que gira a la misma velocidad de nuestro planeta. Lo anterior se da como resultado de la unión de la fuerza centrífuga producida por la Tierra y la fuerza propagada en el vacío. Empero, dichas apreciaciones no vinieron a concretarse sino veinte años después con el lanzamiento del satélite ruso Sputnik I, 
en 1957. Como reacción a dicha iniciativa, Estados Unidos decidió lanzar su propio satélite, el Explorer I, para demostrar que el monopolio de las capacidades espaciales no era privilegio de la URSS, sino que ellos también contaban con la tecnología necesaria.

En réplica a la iniciativa estadounidense se dio una serie de negociones entre los distintos gobiernos miembros de Naciones Unidas interesados en el particular. Así nació la Resolución 1721 de la Asamblea General, en la cual se expuso la necesidad de todos los países de acceder al sistema satelital de telecomunicaciones, basados en el principio de la no discriminación. Con fundamento en esta resolución se dio inicio a los acuerdos definitivos de la Intelsat, una red de satélites destinados a la comunicación, ubicada en la órbita geoestacionaria. Con las iniciativas de los distintos países se originó el desarrollo y progreso del sistema de satélites destinados a la telecomunicación, especialmente con la formacióny consolidación de entidades como la UIT, encargadas de regular cada uno de los elementos que integran dicho sistema, como por ejemplo el espectro electromagnético y radioeléctrico ${ }^{10}$.

Expuesto lo anterior, se procederá a explicar los aspectos técnicos relativos a la operación del sistema satelital. Este se compone de un satélite y de las antenas que se encuentran en Tierra (a veces consta de más de un satélite). La cantidad de ambos elementos, es decir, de satélites y antenas depende de la actividad que se

10 Maral, G., Bousquet, M., Satellite Communications Systems, John Wiley \& Sons, 1998. vaya a realizar y el tipo de comunicación que se desea transmitir. Una vez adjudicada una banda de frecuencia específica (para el caso de las empresas privadas prestadoras del servicio), la antena envía una transmisión por dicha banda de frecuencia a través de ondas electromagnéticas. Estas ondas son recibidas por un satélite (transponder ${ }^{11}$ ), el cual debido al fenómeno de la difracción las reenvía a otra antena situada en otra parte del planeta Tierra, en la banda necesaria para su recepción.

Se debe mencionar que los sistemas satelitales de telecomunicaciones operan también en otros tipos de órbitas distintas a la geoestacionaria. Están la órbita LEO u órbita baja, situada entre los 500 y 2.000 km; la órbita MEO o de altura mediana que se ubica entre los 9000 y los 18.000 $\mathrm{Km}$; y finalmente la órbita GEo que va hasta los $50.000 \mathrm{~km}$.

El rol de coordinación que juegan instituciones como la UIT es cardinal, en el sentido de evitar interferencias perjudiciales que produzcan daños en el servicio de las telecomunicaciones. La interferencia puede ser entendida como "el efecto de una energía no deseada debida a una o varias emisiones, radiaciones, inducciones 0 sus combinaciones sobre la recepción en un sistema de radiocomunicación, que se manifiesta

11 "Transponder (transmisor-receptor) es una cadena completa de dispositivos montados sobre un satélite artificial de telecomunicaciones, que permite recibir señales de radiocomunicación emitidas desde cierta región de la Tierra (haz de recepción) en una frecuencia, las convierte a otra frecuencia, las amplifica y retransmite a una cierta zona de la Tierra (haz de transmisión). En tal sentido, las funciones básicas de un Transponder son: traslación de frecuencias, amplificación de la señal y aislamiento de canales adyacentes. Los haces de recepción y transmisión pueden cubrir la misma o diferentes áreas de la tierra". "Transponder". (s. f). Recuperado el 30 de mayo de 2012 a las 6:48p. m. de: http://archivo.mintic.gov.co/mincom/faces/index.jsp?id=1882 
como degradación de la calidad, falseamiento o pérdida de la información que se podría obtener en ausencia de esta energía no deseada"12. Es menester aclarar que, si bien las bandas de frecuencia del espectro radioeléctrico que se trasladan de un lugar a otro sirven para el desarrollo de distintos tipos de telecomunicaciones como la transmisión por radio, entre otras, en lo que respecta a este escrito solo importan aquellas bandas relevantes para los sistemas satelitales. En razón de lo anterior, se comprende la necesidad de llevar a cabo la explicación realizada.

Después de haber conceptualizado los aspectos técnicos del espectro electromagnético y radioeléctrico y de haber mencionado la importancia de la existencia de un cuerpo normativo que estructure el funcionamiento de tales espectros, se procede a presentar el segundo bloque del presente escrito, a saber: el desarrollo jurídico y normativo contentivo de las regulaciones aplicables al espectro electromagnético y radioeléctrico.

\section{NORMAS INTERNACIONALES APLICABLES AL MANEJO DEL ESPECTRO ELECTROMAGNÉTICO Y DEL ESPECTRO RADIOELÉCTRICO}

La normatividad internacional en esta clase de temas va de la mano con el desarrollo de áreas tales como la tecnológica y científica. La regulación que se puede llegar a dar en este sentido depende única y exclusivamente de la comprensión que se tenga sobre la utilización y la

12 "Espectro radioeléctrico". (s. f.). Recuperado el 29 de mayo de 2012 a las 7:30 p. m. de: http://www.gobiernoenlinea.gov.co/web/guest/encyclopedia/ composición de elementos que tal vez, desde el punto de vista jurídico, resultan desconocidos y novedosos. Es por esto que este tipo de legislación se da de manera progresiva y gradual, ya que su despliegue no es autónomo ni independiente, sino que se sustenta en el desarrollo de la ciencia.

De igual manera, se debe destacar que el tipo de directrices aplicables pueden ser percibidas como de carácter técnico jurídico, es decir, dichas normas se comprenden desde dos aristas que a pesar de ser distintas se conjugan a la hora de elaborar la ley. Dado que su contenido es eminentemente técnico en cuanto compete a aspectos relativos a la ciencia, a la ingeniería y demás ramas del conocimiento, por el simple hecho de incorporar un deber ser en la sistematización del funcionamiento de esos aspectos técnicos y de fijar un mandamiento explícito para los miembros de la comunidad internacional en lo relativo a esta actividad, es claro su carácter jurídico y la presencia de la figura del derecho de manera imprescindible.

\section{A. Constitución y Convenio} Internacional de Telecomunicaciones $y$ creación de la Unión Internacional de las Telecomunicaciones

Antes de entrar de lleno en los aspectos relacionados con cada uno de los tratados vinculados al tema sub examine, es necesario hablar de la organización internacional de mayor relevancia en el mundo de las telecomunicaciones, a saber: la Unión Internacional de las Telecomunicaciones. Su creación se dio en el marco del desarrollo tecnológico de principios del siglo xIx, lo 
cual explica por qué es la de mayor trayectoria. Con el invento del telégrafo y su rápida adopción, surgió la necesidad de realizar reuniones para fijar acuerdos de interconexión de las redes telegráficas nacionales. Sin embargo, esto no fue suficiente y los distintos Estados nación se vieron en la obligación de suscribir acuerdos bilaterales y multilaterales. Así, para el año 1864 ya existían varios convenios internacionales. En vista de los hechos acontecidos, emergió la iniciativa por parte de veinte Estados europeos de reunirse y desarrollar un acuerdo marco para la interconexión internacional. "En esa misma ocasión, el grupo acordó unas normas comunes que se aplicarían a todos los equipos para facilitar la interconexión internacional, estableció también normas de explotación que habrían de respetarse en todos los países y fijó normas internacionales en materia de tarifas y contabilidad"13. Posteriormente, la organización experimentó una serie de cambios debido al nacimiento del teléfono y de todas las radiocomunicaciones. Pero fue en Madrid, en el año 1932, que el organismo decidió fusionar el Convenio Telegráfico Internacional de 1865 y el Convenio Internacional de Radiotelegrafía de 1906 en el que hoy por hoy se conoce como el Convenio Internacional de las Telecomunicaciones, documento fundador de la Unión Internacional de las Telecomunicaciones, denominación que se empezó a usar el 1 de enero de 1934. De acuerdo con la información sobre la uIT, este nuevo nombre se eligió porque reflejaba adecuadamente el alcance de las funciones de la Unión, que para

13 "Unión Internacional de las Telecomunicaciones". Recuperado el 3 de mayo de 2012 a las 6:30 p. m. de: http://www.itu.int/es/history/overview/Pages/history.aspx aquel tiempo se extendía a todos los medios de comunicación alámbricos e inalámbricos ${ }^{14}$.

El 15 de noviembre de 1947 la institución pasó a ser parte de los organismos especializados de la Organización de Naciones Unidas, mediante la aprobación de un acuerdo en la Asamblea General de la onu. En la actualidad, la estructura de la uाt se compone de los siguientes órganos: Conferencia de Plenipotenciarios, Consejo, Secretaría General, Conferencias de Radiocomunicaciones Mundiales y Regionales, Asambleas de Radiocomunicaciones, Junta del Reglamento de Radiocomunicaciones, Comisiones de Estudio y Grupo Asesor de Radiocomunicaciones, Oficina de Radiocomunicaciones, Asambleas Mundiales de Normalización de las Telecomunicaciones, Comisiones de Estudio y Grupo Asesor de Normalización de las Telecomunicaciones, Oficina de Normalización de las Telecomunicaciones, Conferencias Mundiales y Regionales de Desarrollo de las Telecomunicaciones, Comisiones de Estudio y Grupo Asesor de Desarrollo de las Telecomunicacionesy la Oficina de DesarroIlo de las Telecomunicaciones ${ }^{15}$.

Los instrumentos jurídicos aludidos, a saber, la Constitución y el Convenio de la uit fueron firmados el 22 de diciembre de 1992 en la ciudad de Ginebra, y entraron en vigor el 1 de junio de 1994. Tanto la Constitución como el Convenio han sufrido una serie de enmiendas. La primera de estas tuvo lugar en la Conferencia de Plenipotenciarios de Kyoto, de 1994; la segunda en

\footnotetext{
14 Ibídem

15 Ibídem
} 
Minneapolis en el año 1998, y la última en Marrakech, en vigor desde el año 2002. De acuerdo con la información proveída por el Ministerio de las Tecnologías de la Información y las Comunicaciones, a la fecha de realización de esta tesis el Estado colombiano solo había ratificado las modificaciones planteadas en la Conferencia de Minneapolis (1998), de lo cual se deducen las consecuencias jurídicas derivadas de la no ratificación de la Conferencia de Marrakech.

Ambos instrumentos jurídicos (el Convenio y la Constitución) se rigen por el Convenio de Viena de 1969, lo cual indica que cualquier cambio que se vaya a ejecutar respecto a su estructura dependerá de las prerrogativas señaladas en este tratado. En el caso de las enmiendas mencionadas se aplicó lo establecido en el Capítulo IV, artículos 39, 40 y 41 del Convenio de 1969.

Visto lo anterior se procede a tocar los puntos concernientes al espectro radioeléctrico en el marco de dichos tratados. En su artículo primero, numeral 2, la Constitución de la uIT señala lo siguiente:

efectuará la atribución de las bandas de frecuencias del espectro radioeléctrico y la adjudicación de las frecuencias radioeléctricas, y llevará el registro de las asignaciones de frecuencias y las posiciones orbitales asociadas en la órbita de los satélites geoestacionarios, a fin de evitar toda interferencia perjudicial entre las estaciones de radiocomunicación de los distintos países (...) coordinará los esfuerzos para eliminar las interferencias perjudiciales entre las estaciones de radiocomunicación de los diferentes países y mejorar la utilización del espectro de frecuencias radioeléctricas y de la órbita de los satélites geoestacionarios por los servicios de radiocomunicaciones.

Es claro que uno de los principales aspectos a tratar por parte de la uाt tiene que ver con la regulación del espectro y las posiciones orbitales. Dentro del ámbito de las telecomunicaciones satelitales está el manejo del ROE, el cual tiene relación directa con la órbita geoestacionaria cuya ubicación aproximada está a 36,000 kilómetros de la Tierra, en la misma circunferencia del Ecuador, lo que la hace un recurso natural limitado. El atractivo de esta órbita sobre las de otro tipo radica en que, por su posición relativa sobre la Tierra, ejerce una atracción física que hace que los satélites se muevan a la misma velocidad de la del planeta y conserven de manera permanente su posición respecto al área de cobertura, como se explicó en la primera parte del trabajo.

El ROE es administrado por la UIT con base en los procedimientos establecidos en el Reglamento de las Radiocomunicaciones, el cual como se mirará con posterioridad contempla, entre otros, los procesos de coordinación con otros países que ya tengan satélites operativos o redes registradas ante la organización, para garantizar que no se les generen interferencias perjudiciales.

En concordancia con lo dispuesto en el artículo 1 de la Constitución de la uIT, sobre el funcionamiento en caso de asignación de segmento de órbita geoestacionaria y de frecuencias radioeléctricas, el procedimiento según el Convenio y el Reglamento de Radiocomunicaciones se da de este modo: 
1. Antes de dar inicio a cualquier tipo de proceso a favor de la obtención de una asignación de frecuencia para un sistema satelital, la administración interesada o el representante del grupo de administraciones interesadas, deberá con anterioridad a la coordinación a la que haya lugar enviar a la oficina de la uit una descripción general del sistema para su publicación en la Circular Internacional de Información de Frecuencias con una prelación máxima de 7 años y no inferior a 2 años de la fecha planeada para la entrada en servicio del sistema satelital.

2. En caso de querer hacer alguna modificación a la propuesta enviada a la uit, para el uso de un satélite geoestacionario que modifique la posición por más de seis grados requerirá que se haga una nueva publicación en la Circular Internacional de Frecuencias.

3. Si por cualquier motivo la uाt encuentra que la información presentada en la solicitud a la Uाт es incompleta, se buscará compleción o clarificación según sea el caso de manera inmediata.

4. La fecha de notificación para que empiece a operar un sistema satelital en caso de no requerir coordinación con otras administraciones no será mayor a siete años desde la recepción de la documentación completa.

5. En cualquier caso que una frecuencia asignada no entre en uso dentro del término de 7 años, la uit le informará a la administración a quien se le dio la asignación con tres meses de antelación al vencimiento de los 7 años que esta expirará.

6. Se podrán solicitar extensiones de tiempo a la uit para el uso de la frecuencia asignada por un periodo de tiempo que en ningún caso podrá ser superior a 6 meses.

Se debe destacar que, efectivamente, el tiempo límite para el uso del ROE asignado es de 7 años. Por ende, una vez que a un país le es asignado un ROE de acuerdo con la información suministrada, este tiene 7 años para hacer uso efectivo del mismo so pena de perderlo.

En este orden de ideas, el principal punto del Convenio en relación con el espectro electromagnético y radioeléctrico tiene que ver con la asignación de frecuencias en la comunidad internacional. Es posible aseverar que dicha función no solo resulta imprescindible para el funcionamiento de las telecomunicaciones en el mundo moderno, sino relevante en el posicionamiento de la uाT como organismo especializado de Naciones Unidas.

\section{A. Tratado de Montreux de 1965 y Conferencia de Plenipotenciarios de la Unión Internacional (Málaga - Torremolinos, 1973)}

El primer desarrollo normativo respecto del espectro radioeléctrico se dio en el marco del Tratado de Montreux, en Suiza, en el año de 1965. Este convenio estableció en su artículo 46 la manera en que el espectro radioeléctrico debía ser concebido y comprendido desde el punto de vista del derecho de las telecomunicaciones y el derecho internacional, al disponer que: “Los Miembros y Miembros asociados reconocen la conveniencia de limitar el número de las frecuencias y el espacio del espectro utilizados al mínimo indispensable para asegurar de manera 
satisfactoria el funcionamiento de los servicios necesarios. A tales fines será conveniente que se apliquen, a la mayor brevedad, los adelantos técnicos más recientes". Sobre dicho mandato se hará referencia en posteriores tratados, Io cual evidencia la relevancia que tiene para los miembros de la uit el espectro y, en consecuencia, la administración que debe darse a este, específicamente cuando se describe la limitación en el número de frecuencias, las cuales deben ser utilizadas al mínimo indispensable. Si bien en dicha convención se habla sobre el espectro, no se dice nada en relación con la órbita geoestacionaria, aspecto tratado en la Conferencia de Plenipotenciarios de la Unión Internacional de Telecomunicaciones de Málaga-Torremolinos (1973).

En dicha conferencia se expusieron los motivos por los cuales el espectro electromagnético es de suma notoriedad para todos los Estados, al igual que las bandas de frecuencia. Asimismo se reconoció que el espectro es un recurso natural limitado, aunque no agotable, de ahí la preponderancia de reglamentarlo en el sentido de limitar el número de frecuencias y el espacio utilizado en las telecomunicaciones vía satelital, con el objetivo de lograr la distribución satisfactoria y razonable necesaria para la prestación de los servicios que requiere el funcionamiento de la sociedad. Si un país no gestiona de forma correcta su espectro radioeléctrico pierde oportunidades para introducir nuevos servicios de telecomunicaciones para sus habitantes, además del atraso en la infraestructura de estas ${ }^{16}$.

16 "Servicios de Telecomunicaciones". (s. f). Recuperado el 3 de mayo de 2012 a las 6:30 p. m. de: http://www.sit.gob.gt/uploads/docs/forms/fre/ ESPECTRONoEXPERTOS.pdf
De igual forma, en dicha Conferencia, específicamente en el marco de los sistemas satelitales de telecomunicación, se hizo la primera alusión al concepto de recurso órbita espectro: “un recurso natural constituido por la órbita de los satélites geoestacionarios u otras órbitas de satélites, y el espectro de frecuencias radioeléctricas atribuido o adjudicado a los servicios de radiocomunicaciones por satélite por la Unión Internacional de Telecomunicaciones (UIT)"17. Cuando se dice que este es limitado tiene que ver con que no es infinito, es decir, que su extensión no es eterna, sino que se encuentra circunscrito a una medida determinada, lo cual conlleva intuir consecuencias tales como la saturación. Sin embargo, cuando se afirma que no es agotable, se refiere a que su existencia como recurso perdura en el tiempo, esto en razón de los avances y desarrollos tecnológicos que permiten su perdurabilidad.

Teniendo en cuenta esto, se puede plantear que el ROE es una integración de los elementos aludidos, los cuales se constituyen en piedras angulares de la comunicación vía satelital. Cuando un satélite se encuentra en un segmento de una órbita geoestacionaria con el objetivo de transmitir una señal de televisión, por ejemplo, a este se le asignan unas frecuencias específicas para que pueda hacerlo en la onda electromagnética correspondiente. Es justamente dicha articulación la que se denomina roe, la cual para cada satélite en órbita puede presentar característi-

17 Acuerdos sectoriales sobre servicios en el hemisferio occidental, específicamente la Decisión 395: Marco regulatorio para la utilización comercial del recurso órbita-espectro de los países miembros con el establecimiento, operación y explotación de sistemas satelitales por parte de empresas andinas. 
cas distintas. Si su misión es ejercer funciones de teleobservación, SU ROE es distinto al de un satélite que se encuentre en otro segmento de la misma órbita y que, en vez de desempeñar funciones de teleobservación se dedique a enviar señales de radio; en pocas palabras, el roe varía de acuerdo con el sistema satelital.

En la conferencia de Málaga - Torremolinos (1973) se plantearon las primeras prerrogativas respecto al uso y gestión alrededor de este recurso; posteriormente, en el Tratado de Nairobi de 1982, estas se ampliaron. El corolario de dicha convención menciona que el empleo y repartición del recurso órbita espectro debe darse de forma eficaz y económica y el acceso debe ser equitativo entre los diferentes países o grupos de países. El artículo 33 establece lo siguiente:

Los Miembros procurarán limitar el número de frecuencias y el espectro utilizado al mínimo indispensable para asegurar el funcionamiento satisfactorio de los servicios necesarios. A tales fines, se esforzarán por aplicar, a la mayor brevedad, los adelantos técnicos más recientes.

En la utilización de bandas de frecuencias para las radiocomunicaciones espaciales, los Miembros tendrán en cuenta que las frecuencias y la órbita de los satélites geoestacionarios son recursos naturales limitados que deben utilizarse en forma eficaz y económica, de conformidad con lo establecido en el Reglamento de Radiocomunicaciones, para permitir el acceso equitativo a esta órbita y a esas frecuencias a los diferentes países o grupos de países, teniendo en cuenta las necesidades especiales de los países en desarrollo y la situación geográfica de determinados países.

La extensión que se dio en estos términos fue bastante significativa, ya que como se mencionará más adelante, esto representa un avance en términos políticos, específicamente en lo concerniente al acceso al ROE y al espectro radioeléctrico en general por parte de los países en vía de desarrollo que no son potencias espaciales. Desde la óptica jurídica se puede recalcar que la disposición contenida en el artículo 33 es bastante similar a la del artículo 46 del tratado de Montreux de 1965, lo cual constata lo antes planteado.

En síntesis, la Conferencia de Málaga - Torremolinos es una ampliación de dicha prerrogativa, extendiéndose hasta lo relativo a la órbita geoestacionaria, pero siempre fundamentándose en la columna vertebral fijada en el Convenio de 1965.

\section{Reglamento de las Radiocomunicacionesde la UIT de 1992}

El Reglamento de las Radiocomunicaciones de 1992 resulta ser la culminación de un proceso de ensamblaje jurídico en el que convergen cuerpos normativos desde la convención que tuvo lugar en Atlantic City en 1947. En él se explica de manera técnica todo lo relativo a la forma en que deben ser interpretadas y aplicadas cada una de las disposiciones concernientes a la forma en que, por ejemplo, se deben distribuir las frecuencias del espectro. Según el autor español Miguel Sánchez Blanco, dicho Reglamento 
se constituye en un acuerdo internacional fundamental relativo a las reglas y procedimientos para el funcionamiento de los "equipos radioeléctricos y la resolución de problemas de interferencias perjudiciales". Este reglamento se encuentra en una total revisión y consecuente actualización para poder adaptarlo al desarrollo de las nuevas necesidades de las telecomunicaciones. Tales actualizaciones se llevan a cabo en las Conferencias Administrativas de Radiocomunicaciones que se celebran en el marco de la $\mathrm{UIT}^{18}$.

La última actualización tuvo lugar en Ginebra (1992), en la Conferencia de Plenipotenciarios compuesta por todos los miembros de la uit. Allí se dio origen a tres distintos sectores a saber: el Sector de Desarrollo de las Telecomunicaciones, el Sector de Normalización de las Telecomunicaciones y el Sector de Radiocomunicaciones. Las responsabilidades antes asumidas por el Comité Consultivo Internacional de Radiocomunicaciones y la Junta Internacional de Registro de Frecuencias fueron trasladadas, respectivamente, a la Oficina de Radiocomunicaciones y a la Junta del Reglamento de Radiocomunicaciones (la cual no tiene carácter permanente $)^{19}$. Dentro de las asignaciones que hacen parte de la Oficina de Radiocomunicaciones se incluye, en primer lugar, el procesamiento de las notificaciones de asignaciones de frecuencias, incluida la información sobre posiciones orbitales de satélites geoestacionarios, recibida de las admi-

18 SÁnchez Blanco, Miguel, "Espectro Electromagnético y Radioeléctrico", en Derecho de las Telecomunicaciones, Cremades, Javier, (coordinador), México: Editorial La Ley - Actualidad S. A., Ministerio del Fomento, 1997, pág. 796.

19 Ibídem nistraciones para inscripción en el Registro Internacional de Frecuencias.

Para estos efectos, la Oficina de Radiocomunicaciones dividió el planeta en tres regiones. La región 1 constituida por Europa, África, el Medio Oriente, Mongolia y las Repúblicas de la ex Unión Soviética. La región 2 compuesta por los países del continente americano. A la región 3 corresponde el resto del mundo principalmente Asia y Oceanía. Dicha división resulta ser muy funcional, ya que de acuerdo con esta organización, tal y como se observa en el reglamento, asigna cada una de las frecuencias necesarias para cada servicio en particular, en una serie de cuadros.

Losmecanismos a través de los cuales se da la distribución de frecuencias del espectro radioeléctrico se pueden sintetizar en tres: la atribución, la adjudicación y la asignación. El primero de estos, la atribución, tiene que ver con la inscripción en el Cuadro de atribución de bandas de frecuencias, de una banda de frecuencia determinada para su utilización en un sistema de comunicación satelital en particular. De acuerdo con el reglamento existen dos tipos de atribución: exclusiva, cuando la banda de frecuencias en cuestión se atribuye a un único servicio de radiocomunicación; compartida, cuando la banda de frecuencias se atribuye a dos o más servicios de radiocomunicación ${ }^{20}$. Las atribuciones exclusivas se otorgan en aquellos casos en los que se produce una amplia utilización internacional

20 "Adjudicación y asignación del espectro radioeléctrico". (s. f). Recuperado el 29 de mayo de 2012 a las 2:30 p. m. de: http://es.wikitel. info/wiki/La_atribución,_la_adjudicación_y_la_asignación_del_espectro_radioeléctrico. 
del sistema en cuestión y, por tanto, implican la necesidad de armonizar este uso. Las atribuciones de frecuencias compartidas se aplican para maximizar la utilización del espectro disponible, cuando dos o más servicios de radiocomunicación pueden utilizar la misma banda de forma eficaz.

La adjudicación, de acuerdo con lo establecido en este cuerpo normativo, es la inscripción de un canal determinado en un plan adoptado por un foro competente, para ser utilizado por una o varias administraciones en un servicio de radiocomunicación terrenal o espacial, en uno o varios países o zonas geográficas determinadas y según condiciones especificadas.

La asignación es la autorización que da una administración para que una estación radioeléctrica utilice una frecuencia o un canal radioeléctrico determinado en condiciones especificadas. “En este sentido, los planes de adjudicación y de asignación de frecuencias constituyen un mecanismo para preservar los derechos de los distintos estados en el acceso equitativo a recursos radioeléctricos limitados, como son el espectro de frecuencias o la órbita de los satélites geoestacionarios" ${ }^{21}$. El tema, sucintamente planteado, es uno de los muchos que trata el Reglamento de Radiocomunicaciones (las radiocomunicaciones para la navegación marítima, es otro de tantos), sin embargo, para efectos del presente escrito, solo cuenta el capítulo que desarrolla la asignación de frecuencias y los mecanismos correspondientes.

21 Ibídem.
Veamos entonces el estatus jurídico del mencionado Reglamento. En el marco del derecho internacional es un tratado en sí mismo, en la medida en que comporta y contiene una serie de disposiciones cuyo tenor corresponde a una deliberación entre los distintos miembros de la UIT, y su aprobación se da por el consenso de todos ellos.

El artículo 2 a) de la Convención de Viena de 1969, referente a los tratados internacionales dispone: "se entiende por "tratado" un acuerdo internacional celebrado por escrito entre Estados y regido por el derecho internacional, ya conste en un instrumento único o en dos o más instrumentos conexos y cualquiera que sea su denominación particular". De acuerdo con lo anterior, si en principio pareció un anexo al Convenio de dicha organización, es claro que el Reglamento de las Radiocomunicaciones es un tratado en sí mismo.

\section{Tratado de Nairobi de 1982}

A pesar de haber dado los primeros pasos hacia la reglamentación internacional del espectro, (al igual que en el tema relativo a la órbita geoestacionaria), no fue sino hasta el Tratado de Nairobi de 1982 que se registraron los grandes avances para el acceso al segmento de la órbita geoestacionaria y al espectro electromagnético. Si bien antes se habían fijado unas pautas respecto a la gestión que cada uno de los países miembros debía realizar en términos del uso razonable y el acceso al espectro y a la órbita geoestacionaria, en dicho tratado se tomaron posiciones políticas y jurídicas hasta entonces inexistentes. Pos- 
terior a la Conferencia de Málaga -Torremolinos (1979) se presentó una serie de discusiones alrededor de la situación de los países ubicados en la línea del Ecuador, los cuales consideraban que al estar localizados en esta posición geográfica no solo contaban con un mejor derecho respecto al acceso a la órbita geoestacionaria, sino que tenían soberanía sobre ella, en razón de las características físicas y atributos técnicos de dicha órbita.

Por estas circunstancias y por mantenerse los satélites de forma permanente sobre algún país dispuesto en la línea ecuatorial, el debate implicó una gran deliberación política en el marco de la Conferencia de 1979 que dio vía al Reglamento de las Radiocomunicaciones; Colombia, junto con otros países como Ecuador, expuso su punto de vista. Era claro que la comunidad internacional, especialmente las potencias espaciales, no iban a ceder en este sentido.

Después de haber puesto los puntos sobre la mesa, en el año 1982, en Nairobi (Kenia) se tomaron las siguientes medidas: se propuso que la asignación del segmento de la órbita geoestacionaria y, por tanto, de las bandas de frecuencia electromagnética se debía hacer teniendo en cuenta las necesidades de los países en desarrollo (la mayoría de países de la línea del Ecuador corresponden a esta categoría); en el supuesto que dos países, uno desarrollado espacialmente y el otro en vía de desarrollo pretendieran Ilegar a una misma posición orbital, se daría prioridad a este último y la Unión internacional de Telecomunicaciones registraría la posición del país en vía de desarrollo; se introdujo el concepto de situación geográfica especial para determinados países, en referencia precisamente a aquellos que se encuentran sobre el Ecuador; se propuso un régimen jurídico especial en el cual se tuvieran en cuenta los intereses de los países en desarrollo (prioridad o especialidad) en lo relativo a las oportunidades de acceso a la órbita. Si bien dicha proposición nunca fue aprobada, se debe reconocer que antes de Nairobi no existía la posibilidad de exponer estas consideraciones por parte de dichos países, ya que las potencias espaciales no daban oportunidad para que actuaran.

\begin{tabular}{|c|c|}
\hline $\begin{array}{c}\text { Conferencia de Málaga- } \\
\text { Torremolinos } 1973\end{array}$ & $\begin{array}{c}\text { Tratado de Nairobi de } \\
1982 \text { (propuesta) }\end{array}$ \\
\hline $\begin{array}{l}\text { 1. Son recursos naturales } \\
\text { limitados no agotables. }\end{array}$ & $\begin{array}{l}\text { 1. Teniendo en cuenta } \\
\text { las necesidades de los } \\
\text { países en vía de desar- } \\
\text { rollo. }\end{array}$ \\
\hline $\begin{array}{l}\text { 2. Deben utilizarse de forma } \\
\text { eficazy económica. }\end{array}$ & $\begin{array}{l}\text { 2. Y a la situación } \\
\text { geográfica de determina- } \\
\text { dos países. }\end{array}$ \\
\hline \multicolumn{2}{|l|}{ 3. Acceso equitativo. } \\
\hline $\begin{array}{l}\text { 4. Diferentes países o gru- } \\
\text { pos de países. }\end{array}$ & \\
\hline
\end{tabular}

Todo lo mencionado arriba es de relevancia total ya que permite comprender la forma en que se ha estructurado el derecho ultraterrestre y el derecho de las telecomunicaciones a nivel internacional. Esto, en el entendido de que estas ramas del derecho se ven atravesadas por preceptos que, si bien no se refieren de manera explícita al espectro electromagnético y radioeléctrico sí fijan unos estándares sobre la forma en que deben ser concebidos. Como se verá cuando se haga referencia a la normatividad nacional, el 
manejo del espectro en el país parte de varios de los estándares fijados en las conversaciones que, por ejemplo, tuvieron lugar en Málaga - Torremolinos (España). Lo mismo sucede con la asignación de frecuencias, regida por el Reglamento de las Radiocomunicaciones de 1992.

A continuación se procede a desarrollar el tratamiento en la legislación nacional al espectro electromagnético y radioeléctrico, particularmente desde la perspectiva del sistema satelital de telecomunicaciones.

\section{NORMAS NACIONALES APLICABLES AL MANEJO DEL ESPECTRO ELECTROMAGNÉTICO Y DEL ESPECTRO RADIOELÉCTRICO}

En aras de mantener una línea clara, se inicia dando una definición de lo que para la ley coIombiana constituye el espectro electromagnético y radioeléctrico. Posteriormente se hace la diferenciación entre ambos tipos de espectro, el control y el uso que las normas disponen que deben tener. Finalmente se hace alusión a principios tales como la libertad e igualdad en el acceso.

\section{A. Definición constitucional}

La Constitución colombiana en su artículo 75 establece lo siguiente:

El espectro electromagnético es un bien público inenajenable e imprescriptible sujeto a control y gestión del Estado. Se garantiza la igualdad de oportunidades en el acceso a su uso en los términos que fije la ley. Para garantizar el pluralismo informativo y la competencia, el Estado intervendrá por mandato de la ley para evitar las prácticas monopolísticas en el uso del espectro electromagnético.

De la anterior definición se desprenden elementos muy importantes. Primeramente, el espectro es un bien público, es decir, la afectación o el destino que se le otorga no está en cabeza de ningún particular, por el contrario, todos los ciudadanos pueden hacer uso de este bajo los parámetros dispuestos en la ley. Una característica de los bienes públicos es su interés social, lo que significa que los beneficios que eventualmente puedan llegar a reportar deben ser percibidos por toda la población. Según el doctrinante Gustavo Penagos, la limitación al uso del espectro por parte de los particulares ha sido interpretada en razón de que este hace parte del territorio colombiano, conforme al último inciso del artículo 101 de la Constitución y pertenece a la Nación según lo estipula el artículo 102 de la Carta Política: “El territorio con los bienes públicos que de él forman parte, pertenecen a la Nación".

En la sentencia T-081 de 1993 el espectro electromagnético es definido como una "franja de espacio alrededor de la tierra a través del cual se desplazan ondas radioeléctricas que portan diversos mensajes sonoros o visuales. Su importancia reside en ser un bien con aptitud para transportar información e imágenes a corta y larga distancia". En ella se explica también cómo las restricciones que se dan sobre su utilización residen en las "normativas técnicas y físicas que deben ser respetadas para evitar abusos del derecho, interferencias o prácticas monopolísticas". 
Es menester comentar que las disposiciones y regulaciones nacionales concernientes al espectro se reparten a lo largo del ordenamiento colombiano, empezando por la esfera constitucional, tocando la esfera comercial y finalizando en la penal. Así pues, el Código Penal en el Capítulo VI, específicamente en el artículo 257, establece el delito de la prestación, acceso o uso ilegales de los servicios de las telecomunicaciones:

El que sin la correspondiente autorización de la autoridad competente, preste, acceda, o use servicio de telefonía móvil, con ánimo de lucro, mediante copia o reproducción de señales de identificación de equipos terminales a estos servicios (...) En las mismas penas incurrirá el que, sin la correspondiente autorización, preste, comercialice, acceda o use el servicio de telefonía pública básica local, local extendida o de larga distancia, con ánimo de lucro. Iguales penas se impondrán a quien, sin la correspondiente autorización, acceda, preste, comercialice, acceda o use red, o cualquiera de los servicios de telecomunicaciones definidos en las normas vigentes.

A pesar de no referirse de manera explícita al espectro, es lo más cercano que se encuentra en la legislación penal en cuanto a la tipificación que se puede dar por violación a la normatividad de este campo energético. De igual forma, el Decreto Ley 1900 de 1990, el cual se constituye en el Estatuto de las Telecomunicaciones, establece que cualquier red o servicio de telecomunicaciones que opere sin autorización previa será considerado como clandestino. En virtud de esta norma, el Ministerio de Tecnologías de la Información y las Comunicaciones y las autoridades militares y de policía tienen la potestad de suspenderlo y de decomisar los equipos, sin perjuicio de las sanciones de orden administrativo o penal a que hubiere lugar, conforme a las normas legales y reglamentarias vigentes. Asimismo, se consideran infracciones específicas al ordenamiento de las telecomunicaciones, entre otras: 1 . El ejercicio de actividades o la prestación de servicios sin la correspondiente concesión o autorización, así como la utilización de frecuencias radioeléctricas sin permiso o en forma distinta de la permitida. 2 . La instalación, la utilización o la conexión a la red de telecomunicaciones del Estado, de equipos que no se ajusten a las normas fijadas por el Ministerio de Tecnologías de la Información y las Comunicaciones. 3. La producción de daños a la red de telecomunicaciones del Estado como consecuencia de conexiones o instalaciones no autorizadas ${ }^{22}$.

Las restricciones y prohibiciones que se dan en esta dirección indican el valor que tiene para el Estado el espectro. Empero, a pesar de los esfuerzos legislativos, las violaciones son constantes y reiteradas.

\section{B. Asignación de frecuencias}

Es importante anotar que la sentencia C-310 de 1996 desarrolla lo relativo a la asignación de frecuencias, y establece que dicha asignación es la autorización que da una administración para que una estación radioeléctrica utilice una frecuencia o canal radioeléctrico determinado

22 "Espectro Radioeléctrico". (s. f.). Recuperado el 17 de mayo de 2012 a las 4:30 p. m. de: http://www.gobiernoenlinea.gov.co/web/guest/encyclopedia/- 
en condiciones específicas ${ }^{23}$. El Ministerio de Tecnologías de la Información y las Comunicaciones asigna las frecuencias, previa solicitud formulada por el interesado, quien debe aportar el proyecto de rango de frecuencias y las características. El Ministerio realiza el respectivo análisis para determinar la zona y la capacidad de los equipos antes de asignar las frecuencias.

Para cumplir con esta función se creó el Cuadro Nacional de Atribución de Bandas de Frecuencias, considerado una herramienta estructuradora del espectro radioeléctrico por cuanto establece la utilización de este sobre la base de prioridades nacionales, las disposiciones del Reglamento de Radiocomunicaciones y del Convenio de la Unión Internacional de Telecomunicaciones, específicamente a través de la administración, la gestión y el control del espectro. Al respecto, el Decreto 4392 expuso que mediante la Ley 671 de 2001, Colombia, al aprobar el "Cuarto Protocolo anexo al Acuerdo General sobre el Comercio de Servicios, con la Lista de Compromisos Específicos de Colombia Anexa", dado en Ginebra el 15 de abril de 1997, se acoge a lo establecido en materia de administración del espectro radioeléctrico:

6. Asignación y utilización de recursos escasos. Todo procedimiento para la asignación y utilización de recursos como las frecuencias, los números y los derechos de paso se llevarán a la práctica de manera objetiva, oportuna, transparente y no discriminatoria... 4 Por "objetiva" se entiende que la asignación y utilización depende de la disponibilidad del cuadro nacional de frecuencias.
Lo anterior evidencia la articulación y aplicación directa del ordenamiento nacional con las disposiciones que se dan a nivel internacional ${ }^{24}$.

Así pues, la ley colombiana, de acuerdo con los preceptos internacionales, distingue la utilización de las frecuencias para cada uno de los servicios de telecomunicación en particular. En este sentido, la sentencia antes señalada indica que una banda de frecuencias determinada por la uाт puede ser utilizada para uno o varios servicios tales como:

La radio, la televisión, la telefonía, la difusión por cable, el telégrafo, el télex, etc., son algunos de los medios que utilizan el espectro electromagnético para enviar y recibir mensajes, y en general toda clase de datos o información. Por tanto también ven limitada su libertad de fundar medios masivos de comunicación, pues al hacer uso del espectro electromagnético, tienen que subordinarse necesariamente a las normas que lo reglamentan. (...). En este aspecto, las frecuencias pueden servir para diversas modalidades de telecomunicación.

Tal y como se observa, Colombia sigue las directrices establecidas en los Convenios de la Uाт para este tipo de aspectos. En este orden de ideas y de acuerdo con la información suministrada por el Ministerio de Tecnologías de la Información y las Comunicaciones, las disposiciones del Convenio Internacional de Telecomunicaciones, la Constitución de la misma organización y el Reglamento de Radiocomunicaciones de la UIT, adoptado en Ginebra, fueron incorporados a

24 “Imagen". (s. f). Recuperada el 30 de mayo 30 de 2012, a las 8:00p. m. de: http://www.google.com/imgres?q=cuadro+nacional+de+atri bución+de+frecuencias\&num=o.mintic.gov.co/AtribuciondeBandas. JPG\&w=1034\&h=693\&ei=EbbGT-_tJYiE8 
la legislación colombiana a través de la Ley52 de $1995^{25}$, la Ley 873 de $2004^{26}$ y la Ley 514 de $1999^{27}$, respectivamente. Cabe mencionar que, si bien dichos cuerpos normativos cuentan con la potestad para poder regular internacionalmente cada uno de los aspectos relativos al espectro,la responsabilidad de administrar las frecuencias corresponde a cada Estado. Es decir, a pesar de existir unos lineamientos normativos esenciales para el funcionamiento de las telecomunicaciones, desde el punto de vista de la ley internacional son los Estados los encargados de gestionar, administrar y controlar el espectro en sus territorios, con lo cual se denota el respeto al derecho soberano de cada Estado, en la medida en que se armonizan los intereses de la comunidad internacional con la voluntad de cada miembro en particular. A lo anterior hace referencia el preámbulo de la Constitución de la Unión Internacional de las Telecomunicaciones en los siguientes términos: "Reconociendo en toda su plenitud el derecho soberano de cada Estado a reglamentar sus telecomunicaciones y teniendo en cuenta la importancia creciente de

25 Por medio de esta ley se aprueban: la Constitución de la Unión Internacional de Telecomunicaciones, el Protocolo Facultativo sobre la solución obligatoria de controversias relacionadas con la Constitución de la Unión Internacional de Telecomunicaciones, el Convenio de la Unión Internacional de Telecomunicaciones y los Reglamentos Administrativos, adoptados en Ginebra el 22 de diciembre de 1992.

26 A través de la Ley 873 de 2004 se aprueban: el Instrumento de Enmienda a la Constitución de la Unión Internacional de Telecomunicaciones (Ginebra, 1992), con las enmiendas adoptadas por la Conferencia de Plenipotenciarios de Kyoto (1994) y Minneapolis (1998); y el Instrumento de Enmienda al Convenio de la Unión Internacional de Telecomunicaciones (Ginebra, 1992), con las enmiendas adoptadas por la Conferencia de Plenipotenciarios de Kyoto (1994) y Minneapolis (1998).

27 En esta normatividad se aprueban las actas finales de la Conferencia Mundial de Radiocomunicaciones (CMR-95), reunida en Ginebra del veintitrés (23) de octubre al diecisiete (17) de noviembre de mil novecientos noventa y cinco (1995). las telecomunicaciones para la salvaguarda, la paz, y el desarrollo económico de los Estados (...)".

\section{Uso}

Para entender el uso que el Estado le da al espectro debe tenerse en cuenta la noción de servicio público. En el artículo 10 de la Ley 1341 de 2009 se plantea que las telecomunicaciones son un servicio público bajo la titularidad del Estado. Esto conlleva que es precisamente este el que debe determinar la forma en que se va a utilizar el espectro para poder garantizar el acceso de todos los ciudadanos al servicio de las telecomunicaciones. En desarrollo de la Ley 182 de 1995, la Corte Constitucional en sentencia C-318 de 1994 se pronunció diciendo que: bajo el supuesto de que la gestión de un servicio reservado al Estado sea abierto a particulares, la garantía institucional de la libre competencia económica cobra plena vigencia frente a los operadores públicos y privados. De esto se deduce que la prestación del servicio puede ser compartida con particulares por medio de una serie de procesos como los establecidos en la Ley 80 de 1993 y el Decreto 02128 del 15 de septiembre de 2011. Dicha normatividad establece los marcos contractuales a través de los cuales los particulares pueden explotar bienes públicos, tales como el espectro electromagnético.

De acuerdo con la sentencia C-403 de 2010 antes expuesta, en cuanto a las condiciones del permiso de uso del espectro electromagnético se debe mencionar el cumplimiento de los siguientes requisitos: “(i) esté coordinado con las 
políticas del Ministerio de Comunicaciones; (ii) no genere interferencias sobre otros servicios; (iii) sean compatibles con las tendencias internacionales de mercado; (iv) no afecten la seguridad nacional; y (v) contribuyan al desarrollo sostenible".

En lo concerniente al espectro radioeléctrico, si bien el permiso para su uso debe darse de conformidad con el proceso de selección objetiva, la Corte expone así las excepciones que se dan frente a dicha regla:

Si bien el artículo 75 Superior le confiere un amplio margen de configuración al legislador, y en esa medida no existe un único mecanismo a través del cual sea posible lograr la igualdad de oportunidades en el acceso al espectro radioeléctrico y la pluralidad de información, así como evitar prácticas que faciliten la concentración de los medios o monopolios, hasta ahora la jurisprudencia ha encontrado que los mecanismos de selección objetiva sirven de mejor manera a los propósitos fijados por el constituyente. Frente a tal situación, el establecimiento de mecanismos excepcionales de adjudicación directa para otorgar las licencias en el uso del espectro radioeléctrico, a primera vista, parece contrariar lo consagrado en el artículo 75 Superior. Una de las excepciones previstas por el legislador para otorgar de manera directa el uso del espectro electromagnético es la continuidad del servicio, que habida cuenta del carácter de "inherentes a la finalidad del Estado" de los servicios públicos, y frente a la obligación del Estado en la prestación eficaz de los servicios públicos, la excepción resulta no sólo constitucionalmente válida, sino también importante y legítima, toda vez que la fórmula se establece para evitar la suspensión del servicio de telecomunicaciones allá donde, por motivos ajenos a la voluntad de la administración, esté en peligro la continuidad del mismo, lo que inevitablemente constituiría un perjuicio para los usuarios, y si bien la norma no precisa cuándo puede entenderse que está en peligro la continuidad del servicio de telecomunicaciones, en la práctica ese peligro hace referencia a una situación extrema o excepcional, y para que tal regla sea realmente excepcional, la solución prevista en la norma debe tener un carácter temporal. (...) el legislador, haciendo uso de la libertad de configuración normativa, dispuso como regla general el procedimiento de licitación pública para seleccionar a los contratistas del Estado, siendo la igualdad de oportunidades junto con la libre concurrencia, los dos elementos medulares de los procesos de selección objetiva. En el caso de la asignación de bandas del espectro radioeléctrico, la necesidad de que el proceso de asignación emplee el mecanismo que mejor garantice la igualdad de oportunidades y prevenga la concentración de los medios de comunicación en unos pocos, así como las prácticas monopolísticas, privilegia los métodos de selección objetiva frente a aquellas prácticas que facilitan la concentración o el monopolio.

Es claro que el uso del espectro electromagnético debe darse bajo una serie de estándares determinados, en los cuales se garantice la libertad de acceso y la igualdad entre los entes del mercado. La Comisión de Regulación de Comunicaciones, a través del Régimen Integral de Protección de los Derechos de los Usuarios de los Servicios de Comunicaciones (Resolución 3066 de 2011), estableció que para la prestación del servicio público de comunicaciones debían tenerse como fundamento principios como 
el de favorabilidad, el de la buena fe, el de la información, el de calidad, el de libre elección, entre otros. Dichos principios resultan vinculantes para aquellas empresas que prestan servicios de telecomunicaciones.

Asimismo, se extrae de dicha sentencia la prohibición de cualquier tipo de normatividad que propenda la formación de actividades monopolistas por parte de algún particular. Frente a esto el Estado cuenta con poder de intervención sobre la forma en que se debe gestionar el espectro. Un claro ejemplo de dicha intervención es la creación de dos instituciones: la Comisión Nacional de Televisión, encargada de las frecuencias asignadas para la transmisión de televisión (transformada en un nuevo organismo denominado Autoridad Nacional de Televisión) y la Agencia Nacional del Espectro.

\section{Agencia Nacional del Espectro}

Debido a la incidencia que dicha institución tiene sobre el espectro en cuanto es la encargada de su manejo, se dedicará un aparte del presente escrito a su estructura y operación. La Agencia Nacional del Espectro (ANE) es una unidad administrativa especial del orden nacional, adscrita al Ministerio de Tecnologías de la Información y las Comunicaciones. Su objeto es brindar el soporte técnico para la gestión, planeación, vigilancia y control del espectro radioeléctrico, en coordinación con las diferentes autoridades que tengan funciones relacionadas con este ${ }^{28}$. Fue creada mediante la Ley 1341 de 2009,

28 "Agencia Nacional del Espectro". (s. f.). Recuperado el 30 de mayo de 2012 a las 6:00 p. m. de: http://www.gobiernoenlinea.gov.co/web/ guest/encyclopedia/- que en su artículo 26 señala como sus funciones principales, entre otras, las de: 1. Diseñar y formular políticas, planes y programas relacionados con la vigilancia y control del Espectro, en concordancia con las políticas nacionales y sectoriales y las propuestas por los organismos internacionales competentes, cuando sea del caso. 2. Estudiar y proponer, acorde con las tendencias del sector y las evoluciones tecnológicas, esquemas óptimos de vigilancia y control del espectro radioeléctrico, incluyendo los satelitales, con excepción a lo dispuesto en el artículo 76 de la Constitución Política y conforme a la normatividad vigente. 3. Realizar la gestión técnica del espectro radioeléctrico. 4. Investigar e identificar las nuevas tendencias nacionales e internacionales en cuanto a la administración, vigilancia y control del espectro. 5. Estudiar y proponer los parámetros de valoración por el derecho al uso del espectro radioeléctrico y la estructura de contraprestaciones. 6. Apoyar al Ministerio de Tecnologías de la Información y las Comunicaciones en el establecimiento de estrategias para la participación en las diversas conferencias y grupos de estudio especializados de la Unión Internacional de Telecomunicaciones y otros organismos internacionales. 7. Adelantar las investigaciones a que haya lugar, por posibles infracciones al régimen del espectro definido por el Ministerio de Tecnologías de la Información y las Comunicaciones así como imponer las sanciones, con excepción de lo dispuesto en el artículo 76 de la Constitución Política. Como se observa, cada uno de los mandamientos que la ley le ordena ejecutar a la ANE se da de manera tal que se articulan los intereses del Estado colombiano con los principios (elevados ante- 
riormente) que rigen el servicio de las telecomunicaciones en el país.

En conclusión, se puede decir que la ejecución de las acciones depende de las políticas. Si las políticas se dan conforme al derecho internacional como a los parámetros nacionales, es claro que lo que direccionará a la ANE en el ejercicio de sus funciones será la continua conciencia de administrar el espectro al mínimo indispensable para asegurar de manera satisfactoria la prestación de los servicios de las telecomunicaciones.

\section{REFLEXIONES FINALES}

Como primer punto vale la pena recalcar que la diferenciación entre el espectro electromagnético y el espectro radioeléctrico no genera tanta disidencia. Desde el punto de vista técnico, la única disonancia radica en que el espectro electromagnético es un campo energético de mucha más extensión que el espectro radioeléctrico, ya que la cantidad de bandas que maneja es mayor. No obstante, limitarse a la explicación anterior conllevaría una imprecisión, puesto que finalmente el espectro radioeléctrico hace parte integral del espectro electromagnético.

En segundo lugar, de la revisión de la normatividad se puede decir que desde la óptica internacional existe un mayor enfoque hacia el espectro radioeléctrico, en la medida en que es precisamente este el que permite las transmisiones de información vía satelital o terrestre, motivo por el cual cuando se estudian normas de carácter internacional como el Reglamento de las Radiocomunicaciones salen a relucir las características naturales de este.
Por otro lado, vale la pena decir que la trascendencia que tiene el espectro electromagnético y radioeléctrico para las comunicaciones vía satelital es total. En el instante en que se va a instalar un sistema satelital se hace patente la necesidad de un ROE para determinar su funcionamiento, es decir, si no se le asigna a un administrador, sea este un organismo internacional, una empresa o un país, no hay forma de que dicho sistema tenga siquiera inicio. Son precisamente las propiedades intrínsecas de estos campos energéticos las que permiten que señales producidas desde un sitio ubicado en la Tierra puedan ser enviadas a un satélite y este a su vez las reenvíe a una ubicación distinta (como se explicó antes, las ondas electromagnéticas pueden propagarse hasta en el vacío).

Con respecto a la normatividad nacional, es claro que el desarrollo jurisprudencial ha permitido que preceptos constitucionales como los consagrados en el artículo 75 tengan un gran alcance. Si se examina de manera detenida dicho artícuIo, es fácil encontrar que la Corte Constitucional e incluso el legislador han ampliado cada uno de los puntos constitutivos de este. En este sentido, la definición de conceptos jurídicos como la gestión del espectro, el control y el uso de este otorgan claridad y concordancia con la normatividad internacional. De igual forma se puede observar que existe una gran consonancia entre lo enunciado en el plano internacional y el nacional. Lo anterior evidencia que, efectivamente, los convenios y demás instrumentos internacionales cuentan con el valor que les concede el bloque de constitucionalidad colombiano. 
Sin embargo, si bien se observa un esfuerzo por parte del Estado en cuanto a lograr una regulación amplia sobre el tema, se puede señalar que existen vacíos especialmente en lo tocante al tema de las frecuencias, en caso de construir un nuevo sistema satelital para Colombia. Recientemente, el Ministerio de Tecnologías de la Información y las Comunicaciones y el Comité de Contratación SATCOL han puesto de presente una clara carencia respecto de estos intereses. En caso de que efectivamente dichos intereses cobren vuelo y logren cristalizarse, se debe tener en cuenta la siguiente apreciación: actualmente Colombia cuenta con $800 \mathrm{MHz}$ que se distribuyen en $300 \mathrm{MHz}$ en banda C (banda de frecuencia radioeléctrica) y $500 \mathrm{MHz}$ en banda planificada (terrestre). La banda C está actualmente saturada en las posiciones que serían adecuadas para Colombia y, por ende, la utilización de los $300 \mathrm{MHz}$ requiere niveles de coordinación que hacen imposible su explotación. Los $500 \mathrm{MHz}$ en banda planificada, a pesar del potencial inmenso por los beneficios de banda ancha que tiene, han tenido una baja explotación comercial.

Por lo tanto, las alternativas para Colombia, en caso de que efectivamente se vaya a ejecutar una iniciativa de este estilo, son en su orden: acudir a la uाт y bajo los procedimientos del Reglamento de las Radiocomunicaciones conseguir un ROE en banda no planificada, para que pueda atender las necesidades de las telecomunicaciones a nivel nacional; acudir al mercado internacional y conseguir el ROE faltante en banda no planificada para complementar la banda planificada de Colombia; adquirir un ROE que tenga la posición adecuada y provea la totalidad de banda requerida para satisfacer las necesidades de las telecomunicaciones en el país. Es clara la relación relevancia del espectro vs. desarrollo de las telecomunicaciones. En el caso colombiano, la presencia de un sistema, ya sea satelital o terrestre, es definitiva, considerando que del desarrollo de su infraestructura depende el acceso al nuevo conocimiento y, por consiguiente, el crecimiento a nivel social, educativo, cultural, político y económico.

Como conclusión, y dando respuesta al interrogante planteado al inicio, ¿cuál es la relevancia que tiene para el funcionamiento de las telecomunicaciones a nivel satelital las regulaciones existentes, tanto a nivel nacional como internacional?, se puede decir que su importancia radica en que la normatividad nacional e internacional provee una coordinación y una estructura indispensable a la hora de administrar el espectro electromagnético y radioeléctrico. Tal como se evidenció de manera constante y como se expuso en los tres últimos puntos de estas reflexiones, la presencia de instituciones como la uाт a nivel internacional y la Agencia Nacional del Espectro a nivel nacional resulta primordial al momento de dar aplicación a preceptos como la igualdad de acceso al recurso como tal. Claros ejemplos son: la jurisprudencia de la Corte Constitucional en lo referente al proceso de selección en caso de asignación de bandas de frecuencia, y la preferencia que tienen los países en vía de desarrollo en la obtención de un segmento de la órbita geoestacionaria.

En concordancia con lo anterior, durante el desarrollo de la presente tesis se ha puesto de pre- 
sente que la esencia técnica constantemente aludida requiere de manera primordial una regulación específica. Las normas en torno a este tema son, como se ha mencionado, de carácter técnico jurídico, pues a pesar de circundar aspectos meramente científicos, se encuentran incorporadas en mandatos que sistematizan la forma en que deben entenderse y aplicarse aquellos preceptos técnicos.

Como se ha venido observando, a pesar de que el objeto que se regula es inasible, esto no implica que el derecho se constituya en un ente ajeno y desconocedor de un tema como el desplegado en este escrito. Por el contrario, objetos de estudio y de necesaria regulación, como por ejemplo el espectro, se constituyen en un cuerpo más de análisis. Si existe el derecho penal, el derecho comercial, entre otras ramas, es claro que el avance de la ciencia y la evolución de la sociedad han conllevado la evolución del derecho como una ciencia más y, por ende, se hace necesario el surgimiento de normatividades como la que se ha venido estudiando, a saber: el derecho ultraterrestre y de las telecomunicaciones.

\section{Bibliografía}

Fontal, B., El espectro electromagnético y su aplicaciones, Caracas, Escuela Venezolana para la enseñanza de Química, 2005.

Maral, G., Bousquet, M., Satellite Communications Systems, Reino Unido, John Wiley \& Sons, 1993.
NANDASIRI, J. Maintaining Outer Space for Peaceful Uses, Tokio, United Nations University, 1984.

PENAGOS, G., Los bienes de uso púbico, Bogotá, Ediciones Doctrina y Ley, 1998.

Tapia Salinas, L., Textos internacionales sobre el espacio, Madrid, Consejo Superior de Investigaciones Científicas y Ministerio del Aire, 1966.

Vásquez Seara, M., Derecho y política en el espacio cósmico, Ciudad de México, Universidad Nacional Autónoma de México, 1986.

Introducción al derecho internacional. México, Escuela Nacional de Ciencias Políticas y Sociales, 1961.

Willams, S M., Derecho internacional contemporáneo: la utilización del espacio ultraterrestre, Abeledo-Perrot, 1990.

http://www.upv.es/satelite/trabajos/pracGrupo17/frecuencias.html

http://www.sit.gob.gt/uploads/docs/forms/fre/ ESPECTROnoEXPERTOS.pdf

http://es.wikitel.info/wiki/La_atribución,_la_ adjudicación_y_la_asignación_del_espectro_radioeléctrico.

http://www.gobiernoenlinea.gov.co/web/ guest/encyclopedia//wiki/Enciclopedia\%20 del\%20Estado/Preguntas+y+respuestas+fre cuentes+de+Espectro+Radioeléctrico+en+C olombia;jsessionid=A725453D07594B5B07 2374809118EOC2 